\title{
Real-time imaging of melting and crystallization in poly(ethylene oxide) by atomic force microscopy
}

\author{
R. Pearce and G. J. Vancso* \\ University of Twente, Faculty of Chemical Technology, P.O. Box 217, 7500 AE, Enschede, \\ The Netherlands \\ (Revised 15 May 1997)
}

\begin{abstract}
The processes of melting and crystallization of poly(ethylene oxide) are followed in real time at elevated temperature by atomic force microscopy using a simple hot stage apparatus. Hedritic development at a temperature of $57^{\circ} \mathrm{C}$ is monitored, including the process of lamellar splaying to yield a spherical morphology. Crystal growth kinetics are measured by monitoring the growth of individual lamellae and found to agree with those obtained by conventional optical microscopy. (C) 1997 Elsevier Science Ltd. All rights reserved.
\end{abstract}

(Keywords: poly(ethylene oxide); crystallization; atomic force microscopy)

\section{Introduction}

The study of crystalline morphology in polymer systems aims at understanding the various levels of organization present as well as their temporal development ${ }^{1}$. Historically, electron microscopy has afforded remarkable insight into the structure of semicrystalline polymers. However, this technique requires significant sample preparation (e.g. microtoming or gold coating) and, more importantly, cannot be used to examine the crystallization process as it occurs, i.e. in real time. Rather, such observations are generally restricted to optical microscopy with its inherently lower magnification.

More recently, the family of techniques collectively referred to as scanning probe microscopy (SPM) has proven to be of great utility in the study of polymer morphology and microstructure from the nanometer to the $0.1 \mathrm{~mm}$ size range. (For a recent comprehensive review, see Ref. 2.) Chief among these, with regard to the study of nonconducting materials, is the atomic force microscope ${ }^{3}$. In recent years there has been a rapid increase in the number of literature reports demonstrating the power of the atomic force microscope in the study of polymers ${ }^{4-7}$. In some instances it has proven possible to image individual polymer chains $^{5-7}$ by resolving methyl ${ }^{7,8}$ and methylene ${ }^{9}$ group substituents. In addition to this unprecedented (lattice) resolution, atomic force microscopy (AFM) has the added benefit of simplicity in terms of sample preparation. Noteworthy is the fact that for most applications the need for procedures such as microtoming or gold coating is obviated.

Despite the rapid growth in the number of literature reports discussing AFM studies of polymer morphology, this technique, like electron microscopy, has hitherto proven useful mostly for static measurements. Nevertheless, several efforts have been made at studying real-time kinetic phenomena by AFM. For example, Hansma and co-workers have published images showing real-time clotting of blood protein $^{10}$. In a subsequent publication, Kaupp was able to follow, by AFM, the solid-state photodimerization of cinnamic acid ${ }^{11}$. The morphology and growth of the organic conductor (tetrathiafulvalene) $\mathrm{Br}_{0.76}$ were monitored in situ

\footnotetext{
* To whom correspondence should be addressed
}

by $\mathrm{AFM}^{12}$. More recently, a report has appeared presenting results on time-dependent morphological changes in silver films at temperatures between 30 and $100^{\circ} \mathrm{C}$ as observed by $\mathrm{AFM}^{13}$. Results have also been published of morphological changes in a liquid crystalline polymer upon cooling to $268 \mathrm{~K}^{14}$. While most AFM studies have been performed at temperatures close to room temperature, an instrument capable of operation at cryogenic temperatures has been reported $^{15}$. A review of recent applications of SPM techniques to dynamic studies of polymeric systems has also appeared ${ }^{16}$.

In this report we will present our results relating to the real-time observation by AFM of melting and crystallization in poly(ethylene oxide) (PEO) at elevated temperature. To our knowledge, these represent the first published images of polymer morphology evolution as obtained in real time by AFM on a crystallizable system above ambient temperature conditions. PEO was chosen for this study because of its low melting point $\left(T_{\mathrm{m}}^{0}=69^{\circ} \mathrm{C}\right)$ and because it is among the earliest and best characterized semicrystalline polymers with regard to supermolecular structure ${ }^{17-21}$.

In this work, both height and deflection images are shown. While height images yield the true threedimensional topography $z(x, y)$ of the sample surface, the deflection mode is useful for obtaining a sharp contrast of the features imaged. This sharp feature contrast resembles that observed in TEM images of replicated sample surfaces; however deflection images have the disadvantage that no true quantitative three-dimensional topography of the sample surface can be obtained.

\section{Experimental}

For these studies a small heating stage was constructed, which is a slightly modified form of one that has been described in the literature ${ }^{22}$. A thin (about $200 \mu \mathrm{m}$ ) rectangular Kapton ${ }^{\circledR}$ pad (supplied by Cole Parmer) measuring $2 \mathrm{~cm} \times 1 \mathrm{~cm}$ was used as a heating device. This was fixed onto a metallic atomic force microscope sample disc, provided by the instrument manufacturer, which was in turn fixed onto a second disc using epoxy in a such a manner that a thin air gap (about $2 \mathrm{~mm}$ ) was present between the two. This was to ensure that air flow was possible so as to minimize heating effects on the piezo. The 
heating pad was then connected to a simple d.c. power supply (Voltcraft ${ }^{\circledR}$ model \#2256). A thin copper shielding electrode (about $25 \mu \mathrm{m}$ ) was used, as described in Ref. 22, to prevent problems due to electrical potentials acting on the atomic force microscope tip. Temperature was measured with a small thermocouple ( $\mathrm{K}$ type) and was verified using a melting point standard (benzophenone, $99 \%$ ), which has a well-characterized melting point of $48^{\circ} \mathrm{C}$. The PEO sample was obtained from Aldrich (molecular weight, $2000000 \mathrm{~g}$ $\mathrm{mol}^{-1}$ ) and was reprecipitated from chloroform into cyclohexane. A thin film of this material was then cast from a dilute chloroform solution (2\%) onto the copper electrode of the heating apparatus, which was then placed directly onto the sample stage of the atomic force microscope. A NanoScope III AFM instrument (Digital Instruments, Santa Barbara, CA) was employed together with a J-scanner, which allowed scans of up to $130 \mu \mathrm{m}^{2}$ to be acquired. Contact mode was used with AFM NanoProbe tips made of $\mathrm{Si}_{3} \mathrm{~N}_{4}$ (Digital Instruments) on cantilevers with a nominal spring constant $k=0.38 \mathrm{~N} \mathrm{~m}^{-1}$ (as stated by the manufacturer).

\section{Results and discussion}

The crystallization of polymers from the melt can yield a wealth of morphological forms, the most common being a spherulite (a spherically symmetric array of lamellar crystals). However, in earlier stages of growth, the crystallizing polymer can adopt a structure consisting of roughly parallel and centrally connected lamellar crystals yielding a polygonal appearance when viewed from at least one direction. This stage of development is termed hedritic ${ }^{23}$. Typically, the stack of lamellae, when observed edge-on, appears as gradually splaying and eventually the structure

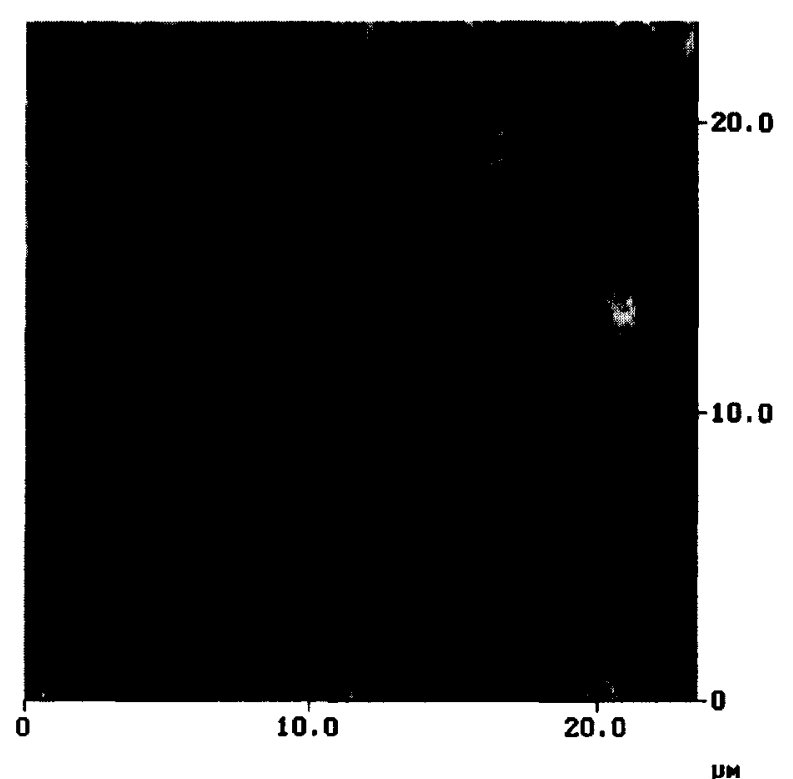

(A)

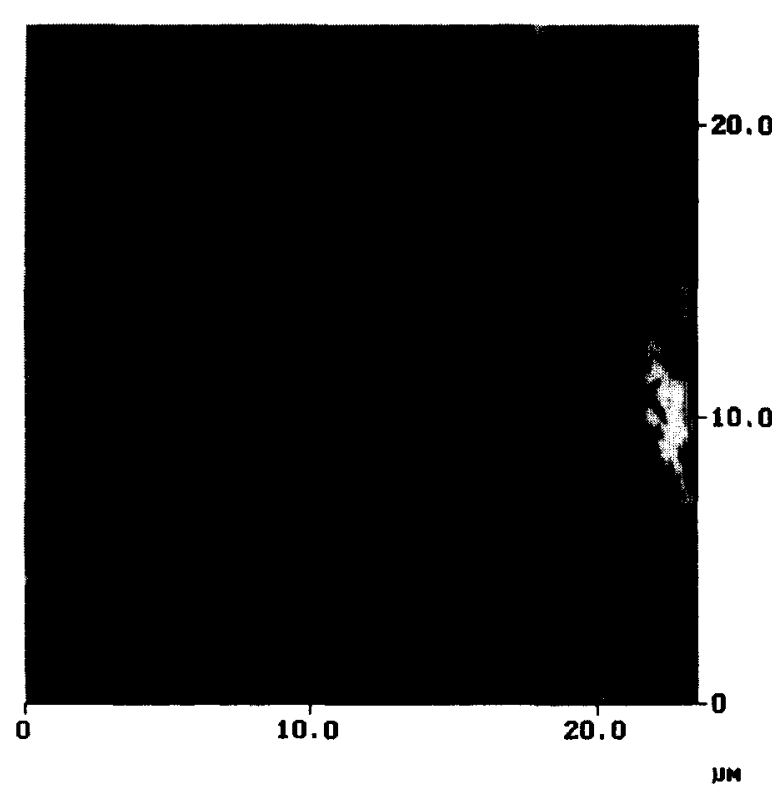

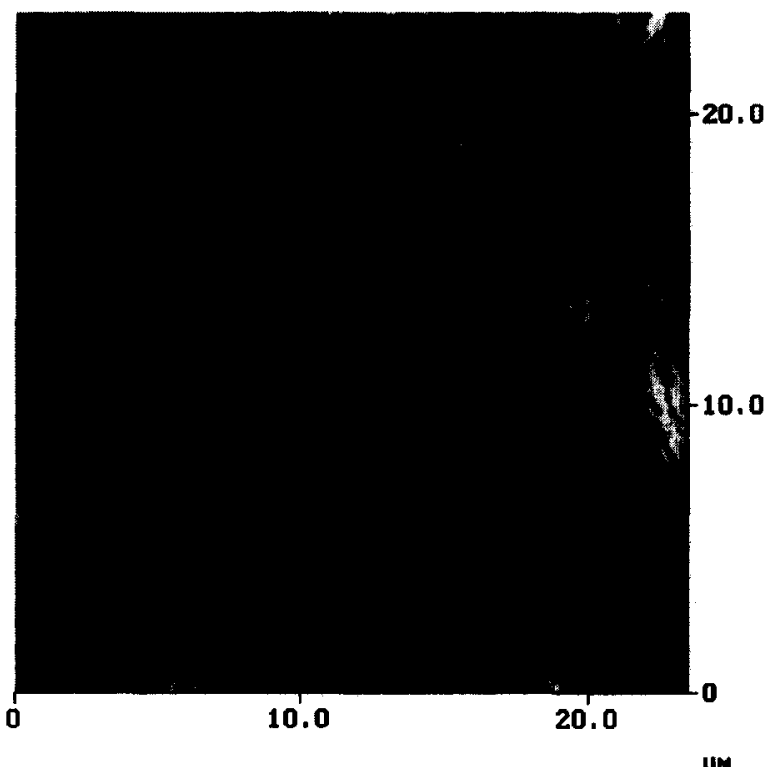

(B)

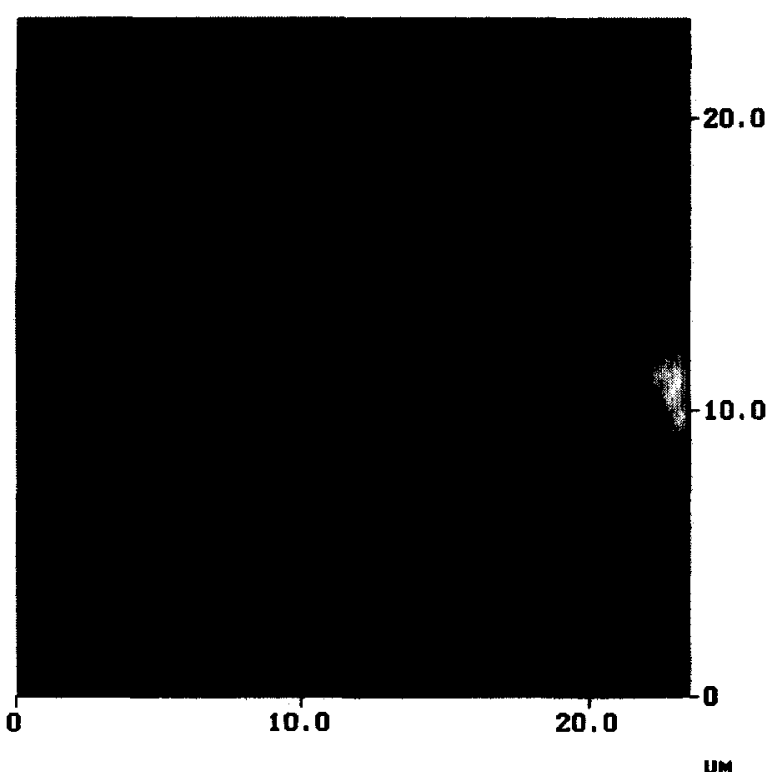

(D)

Figure 1 (A)-(D) AFM deflection images of PEO spherulite grown at $52^{\circ} \mathrm{C}$, obtained at (A) room temperature, (B) $60^{\circ} \mathrm{C}$, and $(\mathrm{C}),(\mathrm{D}), 64^{\circ} \mathrm{C}$ 
closes, yielding central 'eyelets' around the splaying axis ${ }^{24}$. The exact mechanism by which this splaying manifests itself is still not certain. Two possible explanations are the compression of cilia (portions of molecules protruding on the faces of adjacent lamellae) and reptation forces ${ }^{24-26}$.

In Figure 1 can be seen a series of deflection images of a PEO spherulite initially grown at $52^{\circ} \mathrm{C}$. According to the results of Allen and Mandelkern ${ }^{21}$, this temperature is close to the lower limit for hedritic formation of PEO fractions. The image in Figure $1 A$ was acquired at room temperature. The splaying, which is typical of the hedritic morphology, is evident in the upper right-hand section of the image. Much of the lamellar arrangement is visible. For example, approximately $5 \mu \mathrm{m}$ from the left-hand side, and half-way up, one can discern a branch point where five or six 'daughter' lamellae appear to diverge from a common point (probably consisting of a series of parallel dominant lamellae). The roughly linear stack of lamellae at the origin of the hedrite is thought to arise from a process of

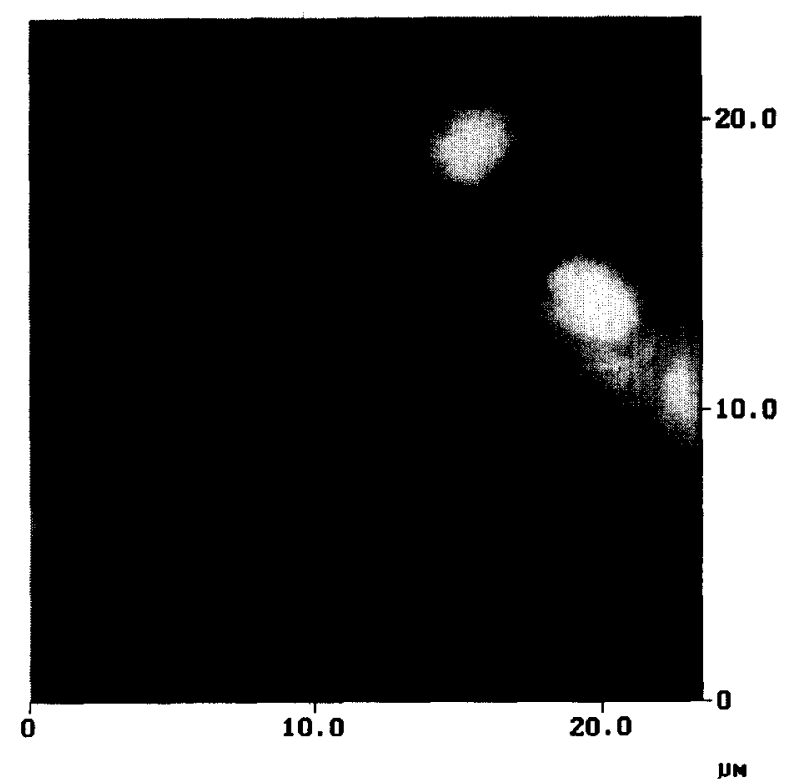

(A)

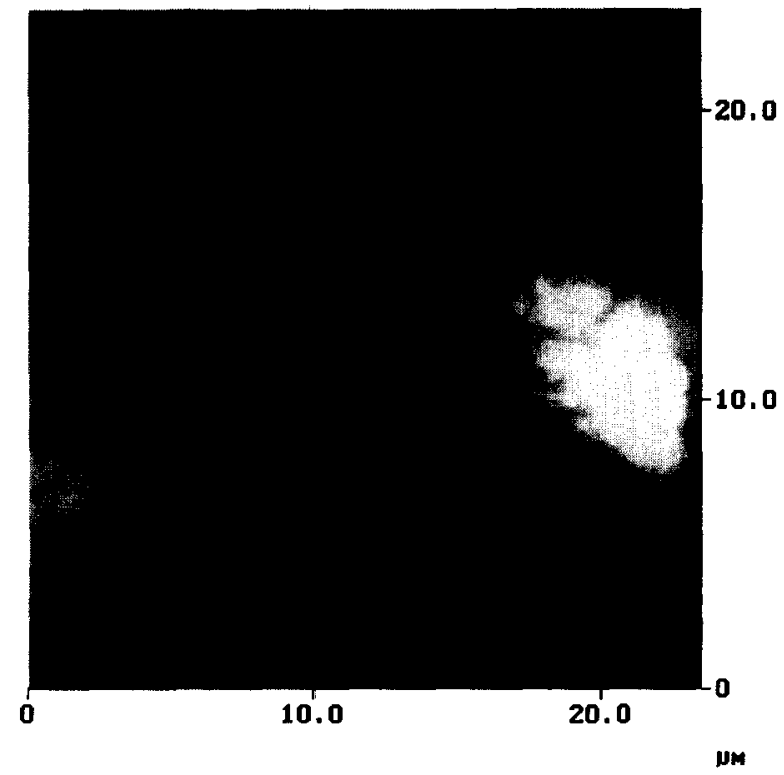

(C) screw dislocations ${ }^{24-26}$. It should be borne in mind that the view shown in Figure $l$ is edge-on to the lamellae.

Figure $1 B$ shows a deflection image of the same region as in Figure $1 A$, but acquired at $60^{\circ} \mathrm{C}$ after approximately $2 \mathrm{~min}$. This temperature is slightly below the melting temperature.

In Figure $1 \mathrm{C}$, the temperature was increased to $64^{\circ} \mathrm{C}$. The scan direction was from bottom to top, and melting is evident at the top of the image. Since this corresponds to a scan rather than a 'snapshot', the bottom portion was in fact acquired approximately $1.5 \mathrm{~min}$ before the upper part. It can be seen that melting is a slow process at this temperature. By comparing Figure $1 C$ and Figure $1 A$, it is apparent that some of the finer details of internal structure are obscured in Figure 1A. It is thought that in addition to dominant and subsidiary lamellae, there is another category of material which crystallizes near the lower temperature limit of the crystallization exotherm ${ }^{26}$, and hence melts at a lower temperature than the remaining material. This is presumably
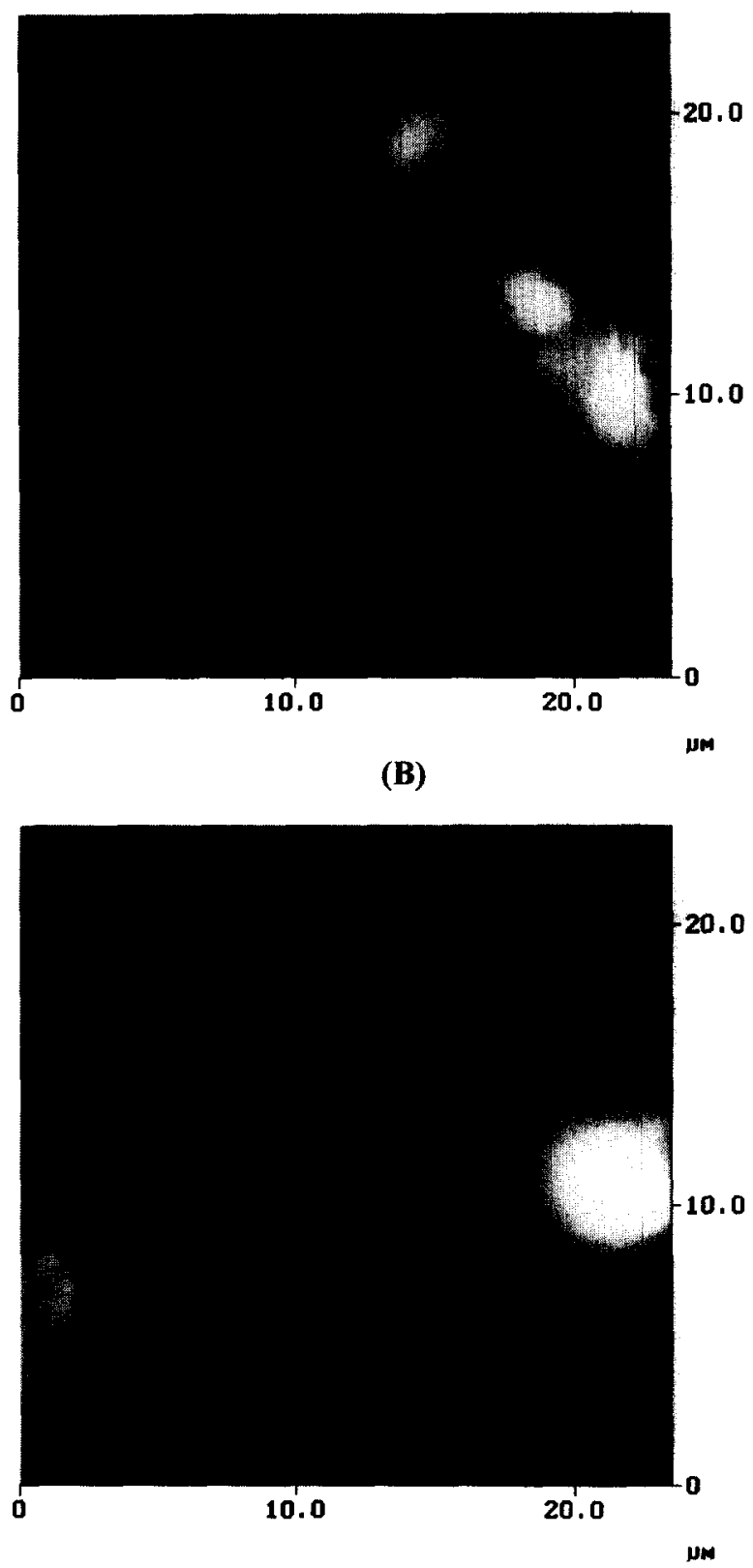

(D)

Figure 2 (A)-(D) AFM height images corresponding to deflection images shown in Figure 1. The verical scale is from 0 to $800 \mathrm{~nm}$ (black to white) 
responsible for the improved resolution of the structure in Figure $1 C$, particularly at the bottom of the image where large-scale melting has yet to occur. This effect can be envisaged as thermal etching. Also noteworthy is the fact that the dominant lamellae, which delineate the main hedritic morphology, remain at least partially visible in the upper part of the image, whilst the remaining structure has melted. Thus at this temperature, the dominant lamellae are more thermally stable, insofar as they melt last. This seems to be consistent with the results of Bassett and Vaughan ${ }^{24}$ who showed the dominant lamellae to be more resistant to chemical etching for polystyrene.

Figure $1 D$ shows the same region as previously shown, after $5 \mathrm{~min}$ at $64^{\circ} \mathrm{C}$. Melting is now seen to be complete and a more or less smooth molten surface remains.
In Figure 2 are shown height images corresponding to the deflection images described above. The former yield directly the changes in the surface topography but have inherently lower lateral resolution than the deflection images. When Figure $2 C$ is compared to Figure $2 A$, it is seen that following partial melting many of the lamellae are in fact protruding above the molten polymer. The origin of this effect is not clear, moreover volume considerations suggest the opposite should occur as the amorphous phase is less dense. Presumably the molten material is capable of flowing sufficiently to fill voids. This is supported by Figure $1 C$, which shows a molten material that has spready laterally as well. This effect is especially noticeable in the area shown in the upper left-hand corner corresponding to the area of impingement between two spherulites.

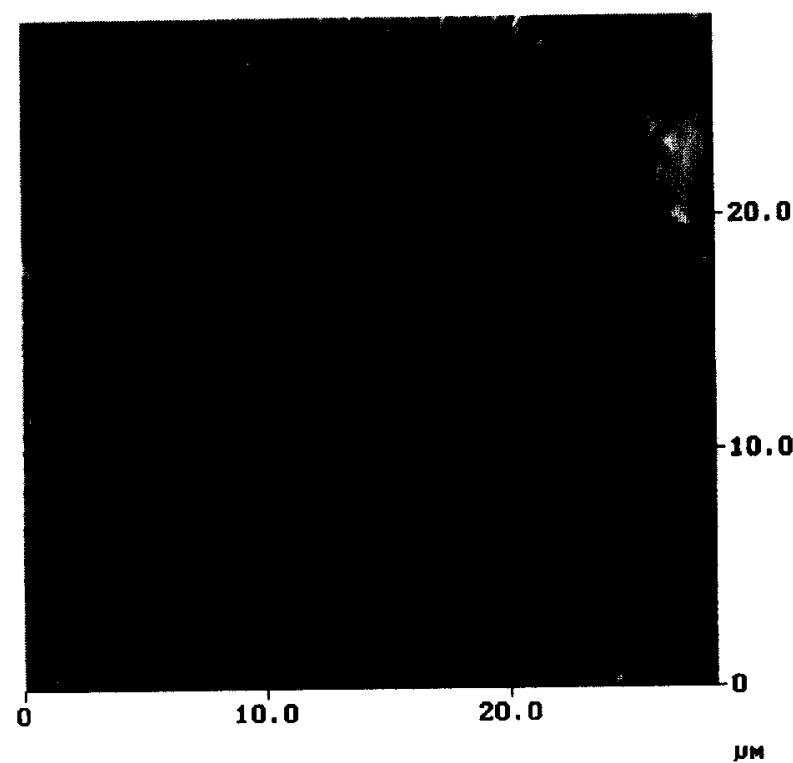

(A)

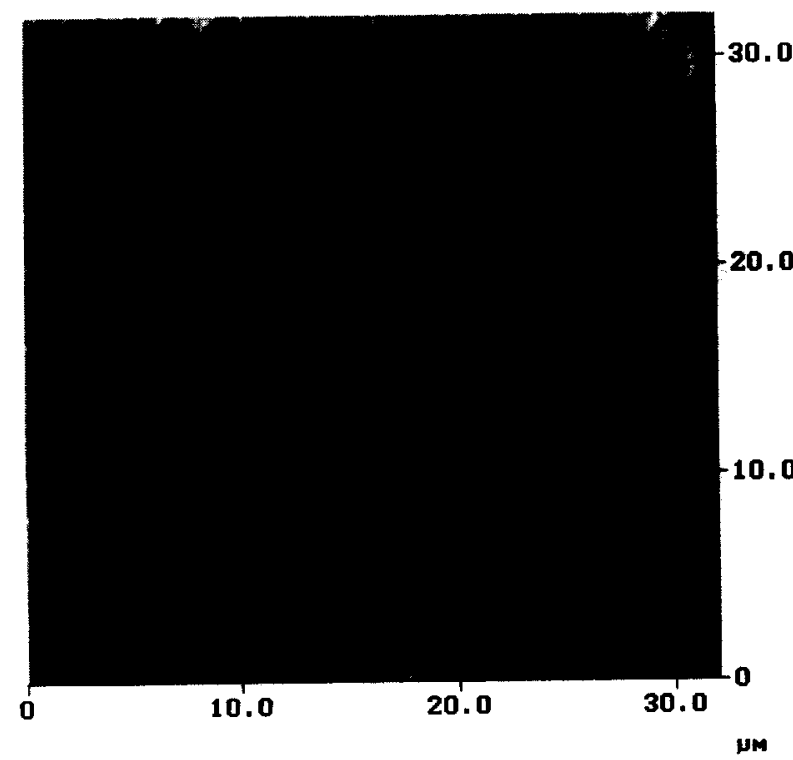

(C)

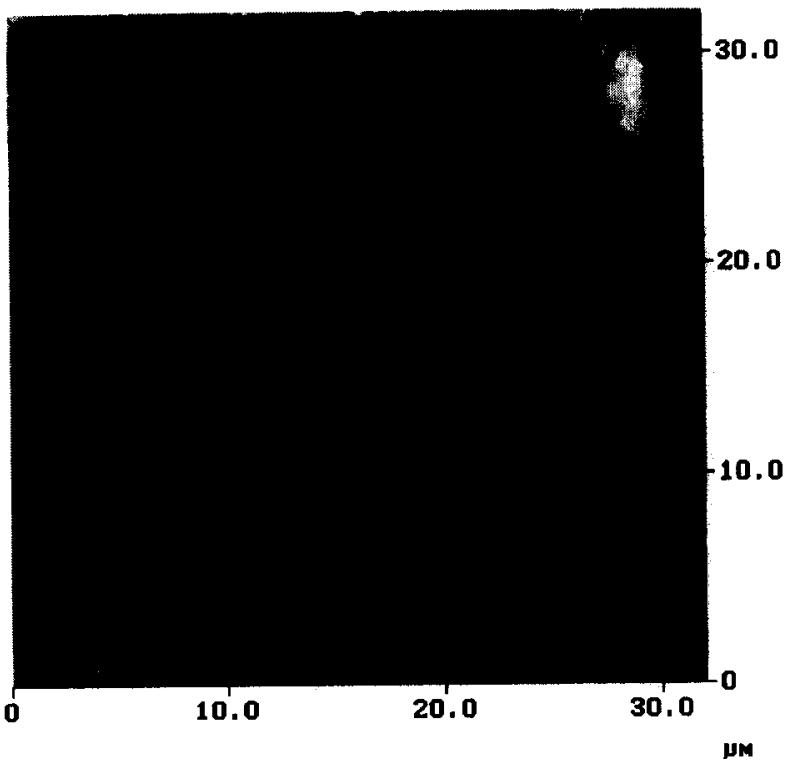

(B)

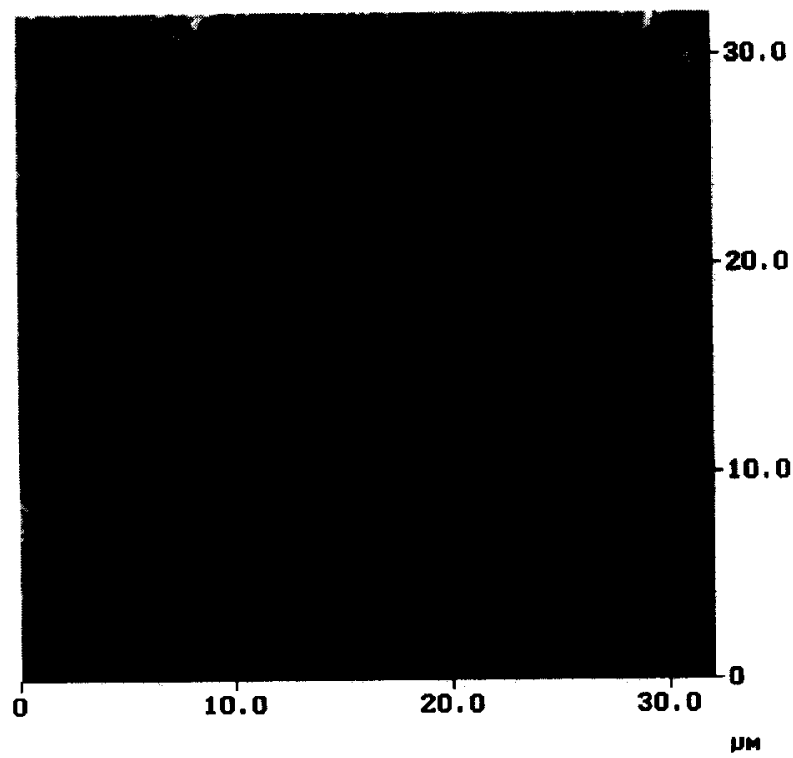

(D)

Figure 3 (A)-(D) AFM deflection images of PEO hedrite growing at $57^{\circ} \mathrm{C}$; the images in (B), (C), and (D) correspond to elapsed times of 7 min, 9 min, and 11 min, respectively, with respect to the image in (A) 
Furthermore, the layers of material below the surface (and closest to the heating surface) would be expected to melt first, thus 'flooding' slightly the upper surface. The brightest spot in Figure $2 D$ corresponds to the heterogeneity that is evident in Figure 1D. However, also evident are the high areas corresponding to the centres of the original 'eyelets' (i.e. the two areas where the splaying lamellae have closed back to form loops). This corresponds to a memory in the melt.

Following the melting at $64^{\circ} \mathrm{C}$, the temperature of the sample was reduced to $57^{\circ} \mathrm{C}$ at which point crystallization and hedritic development could be observed and imaged with lamellar resolution.

In Figure 3 are seen deflection images of a hedritic structure growing at $57^{\circ} \mathrm{C}$. At the stage of growth shown in Figure $3 A$, the splaying of the structure is clear but the central 'eyelets' have not yet filled in. Figure $3 B$ shows the situation $7 \mathrm{~min}$ later. The overall shape has approached circularity and the central portion has begun to fill in by the formation, via secondary nucleation, of straight lamellae which bridge the gap between the two sides of the eyelet. This process continues in Figure $3 C$ and $3 D$, which correspond to elapsed times of $9 \mathrm{~min}$ and $11 \mathrm{~min}$, respectively, relative to the first image. Interestingly, filling-in of the central portion seems to be favoured by the closing of the periphery. It is unclear whether this is a real kinetic effect or simply a consequence of the restricted area available for crystal growth. Estimates of lamellar thicknesses from the corresponding height images yielded values of between one and three times previously reported values obtained by scattering methods $\mathrm{s}^{20,27}$ suggesting, among other things, the presence of lamellar stacks.

It was thought interesting to obtain quantitative measurements of crystal growth rates by AFM, since these are wellknown quantities from optical microscopy. For these purposes, measurements were restricted to crystals growing horizontally on the image, since this circumvented possible errors due to the scan time previously alluded to. At a temperature of $57^{\circ} \mathrm{C}$, a linear growth rate of $7.1 \times$ $10^{-3} \mu \mathrm{m} \mathrm{s}^{-1}$ was obtained. When the measurements were repeated on a conventional optical microscope at the same temperature, a value of $6.1 \times 10^{-3} \mu \mathrm{m} \mathrm{s}^{-1}$ was obtained. This agreement is certainly satisfactory and suggests that the growth rate of the individual lamellae prior to the attainment of sphericity agrees with that of the overall spherulite, as found previously ${ }^{17,18}$ for melt-grown single crystals of PEO.

The differences in density between the crystalline and amorphous phases should give rise to discernible changes in volume across the crystal/melt interface and in fact this expectation is borne out by our measurements. In Figure 4 is shown a plot of sample height as a function of distance along a line connecting the crystal with the melt. Noticeable are the slightly higher heights on the right-hand edge of the trace and the sudden drop in sample height just beyond the interface. The latter corresponds to a depletion zone arising from the three-dimensional contraction of material as it enters the crystal and has been seen previously in a poly( $\beta$-hydroxyvalerate) spherulite ${ }^{28}$ examined by AFM. (It has recently come to our attention that a paper is to appear in which room-temperature growth of a P(HB-coHV) spherulite is discussed ${ }^{29}$. The authors were able, by tapping mode AFM, to obtain lamellar-resolution images of the growth front.) The exact thickness of the polymer sample which remains at the minimum is not known. The asymmetry of the depletion zone is presumably due to the diffusion or reptation of polymer chains from the melt
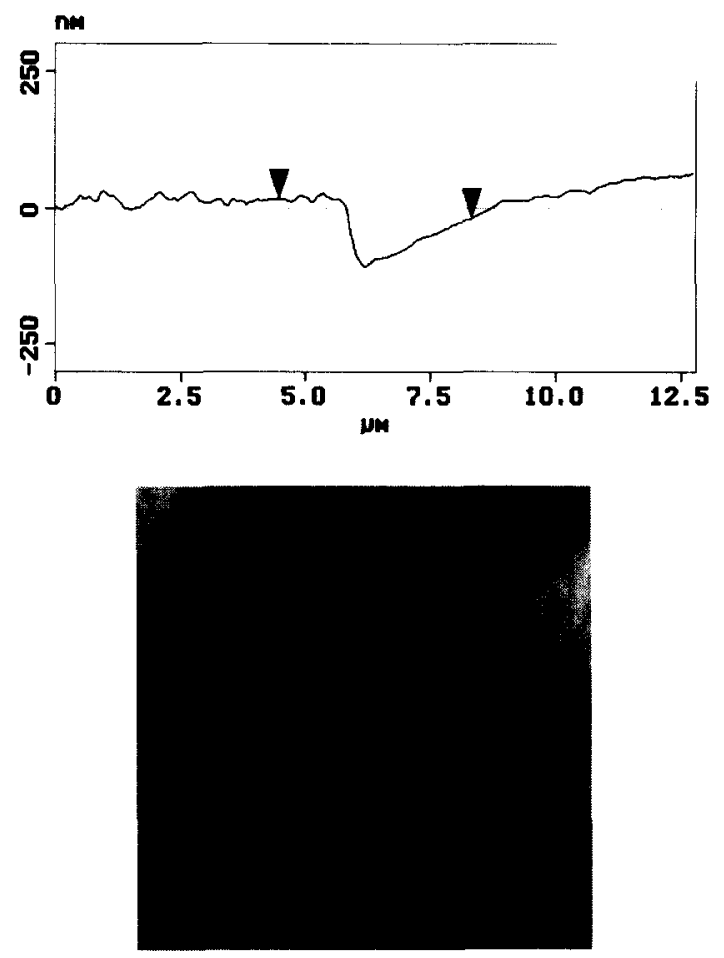

Figure 4 Sample height profile of growing PEO spherulite

towards the interface. As two spherulites approach each other to within a distance of one depletion layer (in the example given, about $2 \mu \mathrm{m}$ ), there will be insufficient material to fill the space between them and this will lead to the frequently observed 'valleys' which form between impinging spherulites (see, for example, the upper left-hand corner of Figure $2 a$ ). The notion of a depletion layer at the interface should not be taken as contradictory to the results of Keith and Padden ${ }^{30,31}$ where the accumulation of impurities occurs at the interface. This is a separate process and can occur independently of any volume changes.

\section{Conclusions}

It has been shown in this report that real-time images of morphological changes, including melting and crystallization of polymers, can be obtained by AFM through the use of a simple hot stage apparatus. This makes possible the study of the kinetic aspects of these processes on a length scale that was previously inaccessible.

\section{Acknowledgements}

The authors are grateful to the University of Twente for financial support, and to Drs. D. L. Trifonova (University of Twente) and M. J. Miles (University of Bristol) for helpful discussions.

\section{References}

1. Wunderlich, B., Macromolecular Physics, Academic Press, New York, 1973.

2. Magonov, S. N., Whangbo, M. H., Surface Analysis with STM and $A F M$, VCH, Weinheim, 1996

3. Binnig, G., Quate, C.F. and Gerber, C.H., Phys. Rev. Lett., 1986, 56, 930.

4. Reneker, D. H. and Chun, I., Polym. Prepr. Am. Chem. Soc., Div. Polym. Chem., 1996, 37(2), 546.

5. Vancso, G. J., Polym. Prepr. Am. Chem. Soc. Div. Polym. Chem., 1996, 37(2), 550. 
6. Magonov, S.N., Qvarnström, K., Elings, V. and Cantow, H.J., Polym. Bull., 1991, 25, 689.

7. Snétivy, D. and Vancso, G.J., Polymer, 1994, 35, 461

8. Stocker, W., Magonov, S.N., Cantow, H.J., Wittmann, J.C. and Lotz, B., Macromolecules, 1993, 26, 5915.

9. Snétivy, D., Yang, H., Glomm, B. and Vancso, G.J., J. Polym. Bull., 1991, 25, 689.

10. Drake, B., Prater, C.B., Weisenhorn, A.L., Gould, S.A.C., Albrecht, T.R., Quate, C.F., Cannell, D.S., Hansma, H.G. and Hansma, P.K., Science, 1989, 243, 1586.

11. Kaupp, G., Angew. Chem. Int. Ed. Engl., 1992, 31, 592.

12. Hillier, A.C. and Ward, M.D., Science, 1994, 263, 1261.

13. Semin, D.J., Lo, A., Roark, S.E., Skodje, R.T. and Rowken, K.L., J. Chem. Phys., 1996, 105, 5542.

14. Magnonov, S.N., Elings, V. and Papkov, V.S., Polymer, 1997, 38 297.

15. Kirk, M.D., Albrecht, T.R. and Quate, C.F., Rev. Sci. Instrum., 1988, 59, 833.

16. Roberts, C.J., Davies, M.C., Shakesheff, K.M., Tendler, S.J.B. and Williams, P.M., TRIP, 1996, 4, 420.

17. Kovacs, A.J. and Gonthier, A., Kolloid Z. Z. Polym., 1972, 250, 530.

18. Kovacs, A.J., Straube, C. and Gonthier, A., J. Polym. Sci., Polym. Symp., 1977, 59, 31 .

19. Kovacs, A.J., Gonthier, A. and Straube, C., J. Polym. Sci., Polym. Symp., 1975, 50, 283.
20. Kovacs, A.J. and Straube, C., Faraday Discuss. Chem. Soc., 1979, 68, 225 .

21. Allen, R.C. and Mandelkem, L.J., J. Polym. Sci., Polym Phys. Ed. $1982,20,1465$

22. Muševič, I., Slak, G. and Blinc, R., Rev. Sci. Instrum., 1996, 67(2), 2554

23. Geil, P. H., Polymer Single Crystals, Wiley Scientific, London, 1963.

24. Bassett, D.C. and Vaughan, A.S., Polymer, 1985, 26, 717.

25. Vaughan, A.S. and Bassett D.C., in Comprehensive Polymer Science, Vol. 2 (eds C. Booth and C. Price), Pergamon Press, Oxford, 1989.

26. Vaughan, A.S., Sci. Prog. Oxford, 1992, 76, 1.

27. Cheng, S.Z.D., Bu, H.S. and Wunderlich, B., Polymer, 1988, 29, 579.

28. McMaster, T.J., Williamson, R.L., Hobbs, J., Barham, P.J. and Miles, M.J., Polym. Prepr., Am. Chem. Soc., Div. Polym. Chem., 1996, 37(2), 553.

29. McMaster, T. J., Hobbs, J. K., Barham, P. J. and Miles, M.J., Probe Microsc, in press.

30. Keith, H.D. and Padden, F.J. Jr., J. Appl. Phys., 1964, 35, 1270.

31. Keith, H.D. and Padden, F.J. Jr., J. Polym. Sci., Polym. Phys. Ed., $1987,25,2371$ 